\title{
Contribuições do GeoGebra nas dialéticas de uma situação didática para o estudo das Medidas de Tendência Central
}

\section{Contributions of GeoGebra in the dialectics of a didactic situation for the study of Central Tendency Measures}

\author{
José Ronaldo Alves Araújo \\ Celina Aparecida Almeida Pereira Abar
}

\begin{abstract}
Resumo: Neste artigo, tecemos reflexões acerca das contribuições do GeoGebra nas dialéticas de uma situação didática envolvendo as Medidas de Tendência Central. Oriundo dos resultados de uma pesquisa de mestrado que teve como objetivo investigar as potencialidades do GeoGebra para o estudo das Medidas de Tendência Central, que foram apresentados no XIII Encontro Nacional de Educação Matemática, sob o ponto de vista teórico. o estudo recorreu às dialéticas de ação, formulação e validação e institucionalização, presentes na Teoria das Situações Didáticas. Numa abordagem qualitativa, adotou-se pressupostos da Engenharia Didática para desenvolver, aplicar e analisar a sequência de atividades. Aplicado a alunos egressos do $9^{\circ}$ ano do Ensino Fundamental, os resultados do estudo apontaram que na proposta das atividades, nas diferentes dialéticas, as múltiplas representações dos dados no GeoGebra constituíram uma vantagem didática que contribuiu para a compreensão e análise dos dados, contribuindo para 0 estudo das Medidas de Tendência Central.
\end{abstract}

Palavras-chave: GeoGebra. Medidas de Tendência Central. Teoria das Situações Didáticas. Engenharia Didática. Múltiplas Representações.

Abstract: In this article we reflect on the contributions of GeoGebra in the dialectics of a didactic situation involving Central Tendency Measures. From the results of a master's research that aimed to investigate the potentialities of GeoGebra for the study of Central Tendency Measures, which were presented at the XIII Encontro Nacional de Educação Matemática. From the theoretical point of view the study resorted to dialectics of action, formulation and validation and institutionalization, present in the Theory of Didactic Situations. In a qualitative approach, Didactic Engineering assumptions were adopted to develop apply and analyze the sequence of activities. Applied to students graduating from the 9th grade of elementary school, the results of the study showed that in the proposed activities, in the different dialectics, the multiple representations of the data in GeoGebra constituted a didactic advantage which contributed to the understanding and analysis of the data, contributing to the study of Central Tendency Measures.

Keywords: GeoGebra. Central Tendency Measures. Theory of Didactic Situations. Didactic Engineering. Multiple Representations.
José Ronaldo Alves Araújo Doutorando em Educação Matemática pelo Programa de Estudos Pós-Graduados em Educação Matemática da Pontifícia Universidade Católica de São Paulo (PUC-SP). Professor da Secretaria de Estado da Educação de São Paulo. São Paulo, Brasil. $\bowtie$ ironaldoaaraujo@gmail.com

Celina Aparecida Almeida Pereira Abar Doutora em Matemática (PUC-SP). Professora do Programa de Estudos Pós-Graduados em Educação Matemática da Pontifícia Universidade Católica de São Paulo (PUC-SP). São Paulo, Brasil. $₫$ abarcaap@pucsp.br

Recebido em 07/08/2019 Aceito em 28/08/2019 Publicado em 01/09/2019 


\section{Introdução}

Este artigo é resultado das reflexões e contribuições dadas ao nosso trabalho apresentado no XIII Encontro Nacional de Educação Matemática (XIII ENEM), realizado em julho de 2019 na cidade de Cuiabá, Mato Grosso, Brasil. Naquela ocasião, discutíamos as contribuições do GeoGebra para o estudo das Medidas de Tendência Central ${ }^{1}$ (MTC), a partir de um recorte da dissertação de mestrado do primeiro autor (ARAÚJO, 2018), na qual foi proposta uma sequência de atividades com suporte do GeoGebra para o estudo das MTC.

O estudo realizado no mestrado utilizou como aporte teórico a Teoria das Situações Didáticas (TSD) de Brousseau (1986), especificamente, foram aportes as dialéticas de ação, formulação e validação e a institucionalização propostas por essa teoria. Naquele trabalho apresentado no XIII ENEM, nos atemos às contribuições do GeoGebra para o estudo dos objetos em questão, que de fato a pesquisa evidenciou em seus resultados e a partir das discussões e reflexões, observamos que essas contribuições se evidenciam, ainda mais, se analisamos à luz dessas dialéticas.

Então, neste artigo, o objetivo é argumentar acerca das contribuições do GeoGebra para o estudo das MTC, conforme as dialéticas oriundas da TSD. Para tal, tecemos considerações acerca da pesquisa desenvolvida no mestrado (ARAÚJO, 2018). As MTC são objetos de estudo da Estatística. Acerca do ensino da Estatística, a Base Nacional Comum Curricular (BNCC) normatiza que

[...] todos os cidadãos precisam desenvolver habilidades para coletar, organizar, representar, interpretar e analisar dados em uma variedade de contextos, de maneira a fazer julgamentos bem fundamentados e tomar as decisões adequadas. Isso inclui raciocinar e utilizar conceitos, representações e índices estatísticos para descrever, explicar e predizer fenômenos (BRASIL, 2017, p. 274).

Com relação às Medidas de Tendência Central (MTC), a sua interpretação se faz necessária no desenvolvimento dessas habilidades citadas pela BNCC, uma vez que o documento também destaca que

[...] os estudantes têm oportunidades não apenas de interpretar estatísticas divulgadas pela mídia, mas, sobretudo, de planejar e executar pesquisa amostral, interpretando as medidas de tendência central, e de comunicar os resultados obtidos por meio de relatórios, incluindo representações gráficas adequadas (BRASIL, 2017, p. 527). 
Nesse sentido, o trabalho desenvolvido no mestrado se justifica e traz como objetivo, desenvolver e aplicar uma proposta de atividades visando à construção de significados das MTC, a partir da mobilização de conhecimentos prévios dos participantes. A proposta recorre ao GeoGebra sob a hipótese de que a interface dinâmica do software possa contribuir para a construção de significados dos objetos abordados.

Bortolossi (2016), se referindo ao GeoGebra, destaca que por meio de suas múltiplas janelas, esse software oferece uma vantagem didática de apresentar, ao mesmo tempo, representações diferentes de um mesmo objeto que interagem entre si e, assim, podem contribuir para a interpretação das MTC. Desse modo, os questionamentos buscaram identificar potencialidades do GeoGebra para o estudo das MTC.

\section{A Estatística na Educação Básica}

No âmbito das propostas curriculares, Batanero (2000) observa que, de maneira geral, a Estatística tem sido incorporada nos currículos de Matemática da Educação Básica. Para essa autora, isso se justifica ao uso recorrente de dados e conceitos estatísticos no cotidiano, assim como em outras disciplinas que o aluno deve cursar, sendo uma necessidade, um conhecimento básico de Estatística em muitas profissões e para o desenvolvimento de pensamento crítico. $\mathrm{A}$ esse respeito, o ensino de Estatística é importante para atender à uma demanda social.

Quanto a essas propostas curriculares mencionadas por Batanero (2000), no contexto do estudo realizado, em relação ao ensino de Estatística na Educação Básica, no estudo trazemos considerações a partir dos Parâmetros Curriculares Nacionais - PCN (BRASIL, 1998), da Base Nacional Comum Curricular - BNCC (BRASIL, 2017) e no Currículo do Estado de São Paulo CESP (SÃO PAULO, 2011).

Lopes (2010) observa que nos PCN, coletar, organizar e interpretar informações é o objetivo das séries finais do Ensino Fundamental. A autora ressalta que, da análise das informações, os alunos devam conjecturar, tirar conclusões, bem como fundamentá-las. A observação de Lopes (2010) vai ao encontro das orientações dos PCN que sugerem, neste nível de ensino, que o aluno seja capaz de ler e interpretar tabelas e gráficos, coletar informações e representá-las em gráficos, fazendo algumas previsões a partir do cálculo das medidas de tendência central (BRASIL, 1998). 
Nesse sentido, a Base Nacional Comum Curricular (BNCC) observa, acerca do ensino de Estatística, que

[...] os primeiros passos envolvem o trabalho com a coleta e a organização de dados de uma pesquisa de interesse dos alunos. 0 planejamento de como fazer a pesquisa ajuda a compreender o papel da Estatística no cotidiano dos alunos. Assim, a leitura, a interpretação e a construção de tabelas e gráficos têm papel fundamental, bem como a forma de produção de texto escrito para a comunicação de dados, pois é preciso compreender que 0 texto deve sintetizar ou justificar as conclusões (BRASIL, 2017, p. 272-273).

O que a BNCC normatiza vai ao encontro do que o currículo paulista traz como expectativas, que 0 aluno desenvolva habilidades de

Construir e interpretar tabelas e gráficos de frequências a partir de dados obtidos em pesquisas por amostras Estatísticas.

Calcular e interpretar medidas de tendência central de uma distribuição de dados: média, mediana e moda.

Calcular e interpretar medidas de dispersão de uma distribuição de dados: desvio padrão.

Analisar e interpretar índices estatísticos de diferentes tipos.

Reconhecer as características de conjuntos de dados distribuídos normalmente; utilizar a curva normal em estimativas pontuais e intervalares (SÃO PAULO, 2011, p. 70).

As habilidades que o currículo paulista destaca, além das normatizações da BNCC e as orientações dos PCN, revelam a necessidade de educar estatisticamente a sociedade, diante das informações que temos acesso, por meio de livros, revistas, televisão, rádio, internet etc. Nesse sentido, é interessante evidenciar que os documentos citados trazem consigo, em relação à Estatística, a possibilidade de coletar, organizar, tratar e analisar resultados obtidos por meio do acesso a essas informações, que justificam a importância de se aprender e entender Estatística, legitimando o nosso interesse nas Medidas de Tendência Central.

\section{As tecnologias digitais e o ensino de Estatística}

Acerca das tecnologias, recorrendo à BNCC, este documento salienta a importância do uso de diversas ferramentas de software e aplicativos para compreender e produzir conteúdos em diversas mídias. Essas tecnologias permitem simular fenômenos e processos das diferentes áreas 
do conhecimento e elaborar e explorar diferentes registros de representação matemática (BRASIL, 2017).

Nesse sentido, como uma das habilidades a ser desenvolvida, a BNCC destaca "construir e interpretar tabelas e gráficos de frequências com base em dados obtidos em pesquisas por amostras estatísticas, incluindo ou não o uso de softwares que inter-relacionem estatística, geometria e álgebra" (BRASIL, 2017, p. 546).

Com relação ao uso de softwares, Abar (2011) tratando de questões sobre a utilização dos recursos tecnológicos, salienta que esses recursos podem permitir situações que simulam 0 real podendo favorecer um aprendizado significativo e desafiador.

Referindo-se ao uso de recursos tecnológicos, para o ensino de Estatística, Ribacionka (2010) observa que os computadores estão presentes também na abordagem da filosofia da análise exploratória de dados com a utilização dos mais diversos softwares, sendo que

[...] o uso destes aplicativos faz com que os alunos reflitam sobre os dados coletados e possam realizar conclusões de uma forma mais dinâmica e não se aterem aos cálculos, necessários para que cheguem a um resultado, também permite a um maior grau de correção dos resultados obtidos (RIBACIONKA, 2010, p. 51)

Nesse sentido, recorrer à utilização de uma tecnologia digital para o estudo das MTC vai ao encontro das considerações de Ribacionka (2010) e Abar (2011). Conforme essas autoras, todas as formas nas quais os computadores são usados em pesquisas, estão potencialmente disponíveis para o ensino e aprendizagem.

Assim, acerca do GeoGebra, Bortolossi (2016) considera que "por meio de suas múltiplas janelas, reúne, em um único ambiente, recursos gráficos, numéricos, simbólicos e de programação em Geometria, Aritmética, Álgebra, Funções, Estatística e Probabilidade" (p. 430). Esse autor destaca que o GeoGebra, por apresentar, ao mesmo tempo, representações diferentes de um mesmo objeto que interagem entre si, constitui-se em uma vantagem didática.

\section{Aporte teórico}

Para os aportes teóricos, a investigação adotou a Teoria das Situações Didáticas - TSD (BROUSSEAU, 1986) sobre a qual Almouloud (2007) assevera que o objetivo é caracterizar um 
processo de aprendizagem por uma série de situações reprodutíveis, conduzindo frequentemente à modificação de um conjunto de comportamentos dos alunos. Conforme destaca o autor, esse

[...] processo de aprendizagem pode ser caracterizado (se não determinado) por um conjunto de situações identificáveis (naturais ou didáticas) reprodutíveis, conduzindo frequentemente à modificação de um conjunto de comportamentos de alunos, modificação característica da aquisição de um determinado conjunto de conhecimentos. (BROUSSEAU, 1975, p. 6, apud ALMOULOUD, 2007, p. 31).

De acordo com Almouloud (2007), nessas situações o saber tem diferentes funções e 0 aluno não tem a mesma relação com o saber, sendo possível observar tempos dominantes, denominadas dialéticas:

A dialética de ação consiste em colocar um problema para o aluno cuja melhor solução, nas condições propostas, é o conhecimento a ensinar; e que o aluno possa agir sobre essa dialética e que ela lhe retorne informações sobre sua ação.

A dialética de formulação consiste quando o aluno interage com uma ou várias pessoas, de modo que há troca de informações. Nessa interação, ele pode ser emissor ou receptor de informações, passadas de forma escrita ou oral, podendo ser apresentadas em língua natural ou matemática, permitindo criar um modelo explícito que pode ser formulado com sinais e regras comuns, já conhecidas ou novas (ALMOULOUD, 2007).

$\mathrm{Na}$ dialética de validação, o aluno apresenta a sua estratégia utilizada para responder o problema proposto, de modo a deixar evidente a validade de sua estratégia. "Nas situações de validação há o contexto de trama de provas ${ }^{1}$ e de formalizações, objetivando a elaboração de uma linguagem mais rigorosa (prova) para convencimento dos interlocutores (pares)" (POMMER, 2013, p. 18).

A institucionalização ocorre quando, uma vez constituído e validado, o novo conhecimento passa a fazer parte do patrimônio matemático da classe. A institucionalização, embora não tenha o estatuto de saber social, ao ser feita pelo professor, esse saber passa a ser domínio do aluno e podendo, em outros problemas matemáticos, ser usado por este aluno (ALMOULOUD, 2007).

${ }^{1}$ Provas aqui entendida como apresentação de elementos que justifiquem o modelo ou raciocínio utilizado pelo aluno na situação didática. 
Essas dialéticas propostas pela TSD nos norteiam para as análises das contribuições do GeoGebra para o estudo das MTC na proposta de atividades, dados os procedimentos metodológicos que tratamos a seguir.

\section{Procedimentos metodológicos}

O estudo tem um caráter qualitativo. Conforme Godoy (1995), esse tipo de estudo ocorre em um ambiente natural como fonte direta de dados e o pesquisador como instrumento fundamental; tem caráter descritivo; tem o significado que as pessoas dão às coisas e à sua vida como preocupação do investigador e um enfoque indutivo.

Para sistematizar a elaboração e aplicar o estudo com a proposta de atividades, o método adotado recorreu a pressupostos da metodologia de pesquisa Engenharia Didática propostos por Artigue (1995). Essa autora define o termo Engenharia Didática como

(...) uma forma de trabalho didático equiparável com um trabalho de um engenheiro que, para realizar um determinado projeto, baseia-se em conhecimentos científicos de seu domínio e aceita submeter-se a um controle de tipo científico. No entanto, ao mesmo tempo, encontra-se obrigado a trabalhar com objetos muito mais complexos que os objetos depurados da ciência e, portanto, tem que abordar com praticamente todos meios disponíveis problemas dos quais a ciência não quer ou não pode levar em conta (ARTIGUE, 1995, p. 33).

Machado (2015) entende a Engenharia Didática como uma metodologia de pesquisa específica, que na concepção de Régine Douady é definida como sendo

(...) uma sequência de aula(s) concebida(s), organizada(s) e articulada(s) no tempo, de forma coerente, por um professor-engenheiro para realizar um projeto de aprendizagem para uma certa população de alunos. No decurso das trocas entre professor e alunos, o projeto evolui sob as reações dos alunos em função das escolhas do professor (DOUADY, 1993, p. 2, apud MACHADO, 2015, p. 234).

Diante dessas considerações, os pressupostos levados em conta, para a elaboração, aplicação e análise da proposta de atividades, dizem respeito às análises preliminares; concepção e análises a priori; experimentação e as análises a posteriori e validação.

Quanto às análises preliminares, as mais frequentes estão relacionadas com a epistemologia dos conteúdos que são abordados, os processos de ensino e seus efeitos, as concepções dos estudantes, das dificuldades e obstáculos que afetam a evolução da aprendizagem e as possíveis restrições que poderão surgir na realização da sequência de 
atividades, de modo que tais análises realizam-se tomando como referência os objetivos da pesquisa (ARTIGUE,1995). No estudo, preliminares análises recorreram aos materiais acessados na revisão da literatura, assim como aspectos relacionados aos objetos de estudo presentes nas estruturas curriculares, que citamos neste texto.

Acerca das análises a priori, Almouloud (2007) observa que tem como finalidade responder a questionamentos, bem como validar hipóteses que surgem a partir das análises preliminares e que leva o pesquisador à construção e análise de uma sequência de situaçõesproblema. Nessa fase, o investigador deve tomar a decisão sobre um determinado número de variáveis presentes no sistema o qual a situação-problema se desenvolve (ARTIGUE, 1995). Conforme apontam Artigue (1995), Almouloud (2007) e Machado (2015), há dois tipos de variáveis: as de ordem geral ou as locais, dependentes do conteúdo matemático estudado.

Na pesquisa desenvolvida no mestrado (ARAÚJO, 2018), as variáveis de ordem geral se referiam às seguintes: uma escola pública como local para a realização da pesquisa; um laboratório de informática como ambiente para o experimento; à utilização de uma tecnologia digital, o GeoGebra; a quantidade de alunos participantes; a quantidade de sessões da pesquisa; a duração de cada sessão; e a entrega da atividade impressa aos participantes.

As variáveis locais se apresentam na forma como se estrutura a proposta: o contexto gerador dos dados a serem tratados; o material de apoio para a realização do tratamento dos dados oriundos de cada atividade no GeoGebra; os questionamentos e os passos a serem seguidos no material de apoio para apresentar uma resposta. Além disso, as diferentes representações dos dados no GeoGebra, os questionamentos em função das representações dos dados e a exigência da descontextualização do saber matemático. Concebemos essa estrutura das atividades, de modo a permitir que os alunos desenvolvam habilidades e competências em relação as Medidas de Tendência Central.

A respeito da fase de experimentação, Machado (2015) indica que essa se inicia no momento quando se dá o contato do pesquisador com os alunos participantes da investigação. Almouloud (2007) considera que este é o momento de colocar em funcionamento o dispositivo construído. Esses autores salientam para a necessidade de uma análise a posteriori local durante o desenvolvimento experimental, de modo a identificar a necessidade de possíveis correções, sendo necessário um retorno à análise a priori, um processo de complementação. No entanto, buscando respeitar, na medida do possível, as escolhas e deliberações feitas na análise a priori. 
É relevante destacar que na pesquisa de mestrado utilizamos das suposições apontadas por Almouloud (2007) e Machado (2015), uma vez que, durante as sessões da pesquisa, fez-se correções, especificamente, na Atividade 3, no que diz respeito à apresentação do conjunto de dados e à estruturação dos questionamentos, respeitando as escolhas oriundas da análise a priori.

Em relação às análises a posteriori e validação, essas são baseadas no conjunto de dados recolhidos ao longo da experimentação (ARTIGUE, 1995). Almouloud (2007) as define como um conjunto de resultados que se pode tirar da exploração dos dados recolhidos e que contribui para a melhoria dos conhecimentos didáticos que se tem sobre as condições da transmissão do saber em jogo. Destacamos ser a partir dessa perspectiva que o estudo realizado nos possibilita, neste artigo, discutir as contribuições do GeoGebra para o estudo das Medidas de Tendência Central (MTC).

\section{Aplicação, análise e resultados}

O estudo consistiu na aplicação de quatro atividades, em quatro sessões de cinquenta minutos. Foram participantes da pesquisa, um grupo de seis alunos, com idades entre 14 e 15 anos, todos egressos do $9^{\circ}$ ano do Ensino Fundamental de uma escola da rede estadual de educação de São Paulo. Na sala de informática, cada aluno utilizou um computador para 0 desenvolvimento das atividades no GeoGebra, que já se encontrava instalado nas máquinas. Em outras oportunidades os alunos faziam uso do software, sem, no entanto, terem trabalhado com dados estatísticos até então. Acompanhava as atividades, um material de apoio, no qual constava os procedimentos para construir as representações dos dados e calcular as MTC de cada atividade.

Ressaltamos que no estudo foram analisadas as respostas de dois alunos d1 e d2, que participaram integralmente das quatro sessões. Os demais participantes por questões de indisponibilidade, não compareceram a todas as sessões e considerando a metodologia adotada, que sugere uma análise de toda a sequência realizada pelos participantes, nos detivemos aos participantes d1 e d2.

Os dados coletados são provenientes das produções dos alunos, ou seja, nas respostas faladas e coletadas por meio de áudios e vídeos e, também, das escritas nas atividades impressas e telas de resolução das atividades no GeoGebra. A seguir, apresentamos os dados da aplicação 
das atividades e considerações quanto aos elementos que apontam para contribuições do GeoGebra no ensino das MTC.

Para a elaboração das atividades, embasados pelos pressupostos da Engenharia Didática, realizamos análises preliminares a partir da literatura revisada, bem como nas propostas curriculares - PCN, BNCC e Currículo de Matemática de São Paulo — - atentos às propriedades dos objetos de estudo, entendendo que "as atividades interdisciplinares e as abordagens transdisciplinares constituem recursos fundamentais para a construção do significado dos temas estudados, contribuindo de modo decisivo para a criação de centros de interesse nos alunos" (SÃO PAULO, 2011, p. 28).

Diante das orientações curriculares, escolhemos temas de conhecimento geral para problematizar as atividades propostas: na Atividade 0 - peso infantil; na Atividade 1 - diferenças salariais; na Atividade 2 - horas de acesso à internet; e na Atividade 3 - esperança de vida ao nascer. Essa última, dividida em três subatividades: 3.1 - abordando o estudo da média, 3.2 abordando o estudo da mediana e a 3.3 - abordando o estudo da moda.

A construção e análises a priori das atividades tomaram como referência as dialéticas da Teoria das Situações Didáticas (TSD), de modo que, a priori, o GeoGebra poderia favorecer não só no tratamento dos dados das atividades, mas, também, nas representações dos dados, contribuindo para que os participantes apresentassem respostas aos questionamentos e, assim, colaborando para o sujeito transitar nas dialéticas da situação, na perspectiva do aporte teórico. Neste recorte de estudo são apresentados detalhes da aplicação do estudo, que apresentam indícios de contribuições do GeoGebra para o ensino das Medidas de Tendência Central (MTC).

\section{ATIVIDADE 0}

Um estudo acerca do peso de crianças foi solicitado pela Secretaria da Saúde de uma cidade. A tabela a seguir mostra pesos em $\mathrm{Kg}$ de 13 crianças de 3 anos, coletados no primeiro dia de trabalho por um agente de saúde com a população de uma comunidade.

\begin{tabular}{|c|c|c|c|c|c|c|}
\hline 16 & 13,8 & 12,9 & 14,5 & 14,3 & 13,4 & 14,5 \\
\hline 14,3 & 16 & 14 & 13,6 & 14,5 & 13,9 \\
\hline
\end{tabular}

De acordo com os dados coletados, determine:
a) Qual o valor da média do peso das crianças?
b) $O$ que o número encontrado representa com relação aos dados? 
c) Qual o valor da mediana em relação ao peso das crianças?

d) O valor encontrado evidencia alguma informação ao olhar para os dados apresentados?

e) Existe o valor da moda quanto ao peso das crianças?

f) Se existe, o que ele representa?

$\mathrm{Na}$ Figura 1, a seguir, ilustra-se os alunos desenvolvendo a Atividade 0 da proposta.

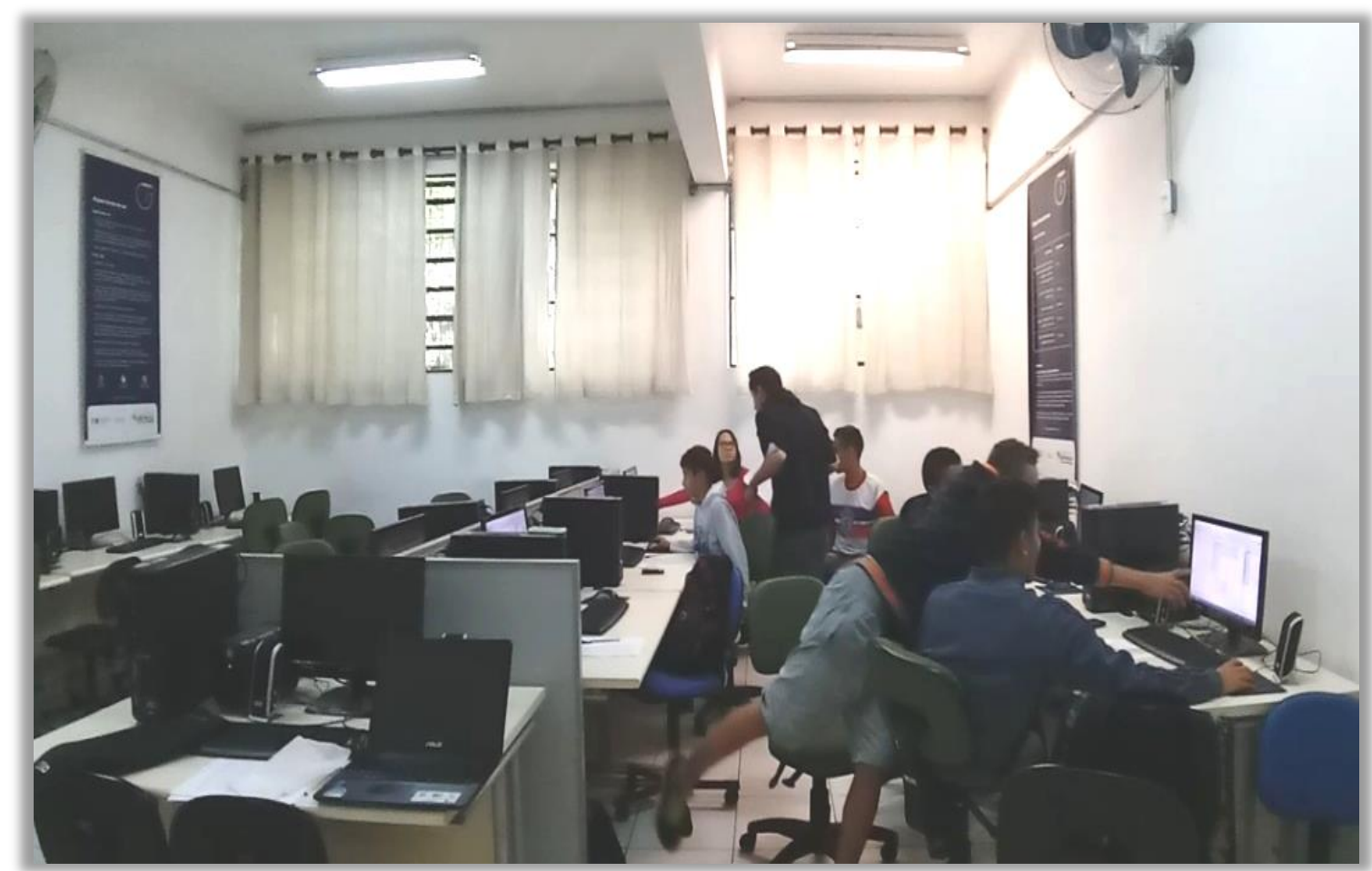

Figura 1: Alunos desenvolvendo a atividade 0 da proposta (ARAÚJO, 2018, p. 74)

Nas atividades da proposta, a qual os alunos foram submetidos, questões práticas como: Qual o valor para a média? Qual o valor para a mediana? Qual(is) o(s) valor(es) para a moda? - estavam em todas as atividades, no entanto ao seguirem os passos das atividades, esses valores se faziam presentes automaticamente, ao toque de um comando.

$\mathrm{Na}$ Atividade 0 , assim como nas outras, ao inserirem os valores na planilha e criarem uma lista com os valores, na janela de álgebra, para encontrar o valor para a média no caso da Atividade 0 , dos pesos das crianças, o comando MEDIA[peso] já o apresentava na janela de álgebra e 0 procedimento para as demais MTC seguia a mesma estrutura.

No entanto, não era interesse do estudo que os alunos apenas se detivessem em encontrar valores para as MTC, mas que houvesse, a partir deles, uma reflexão sobre suas 
representações em relação aos dados de origem. A esse respeito todas as atividades trouxeram questionamentos nesse sentido, fazendo alusão às representações dos dados no software.

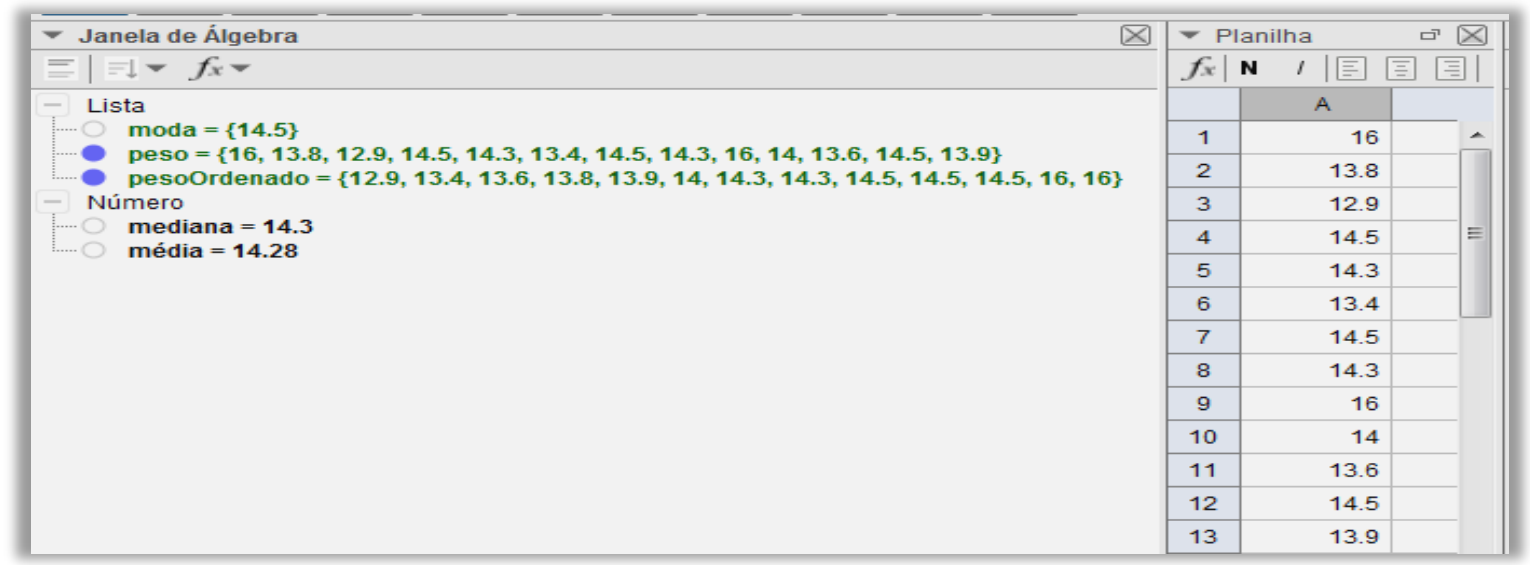

Figura 2: Representações dos dados da atividade 0 no GeoGebra (ARAÚJO, 2018, p. 80-81)

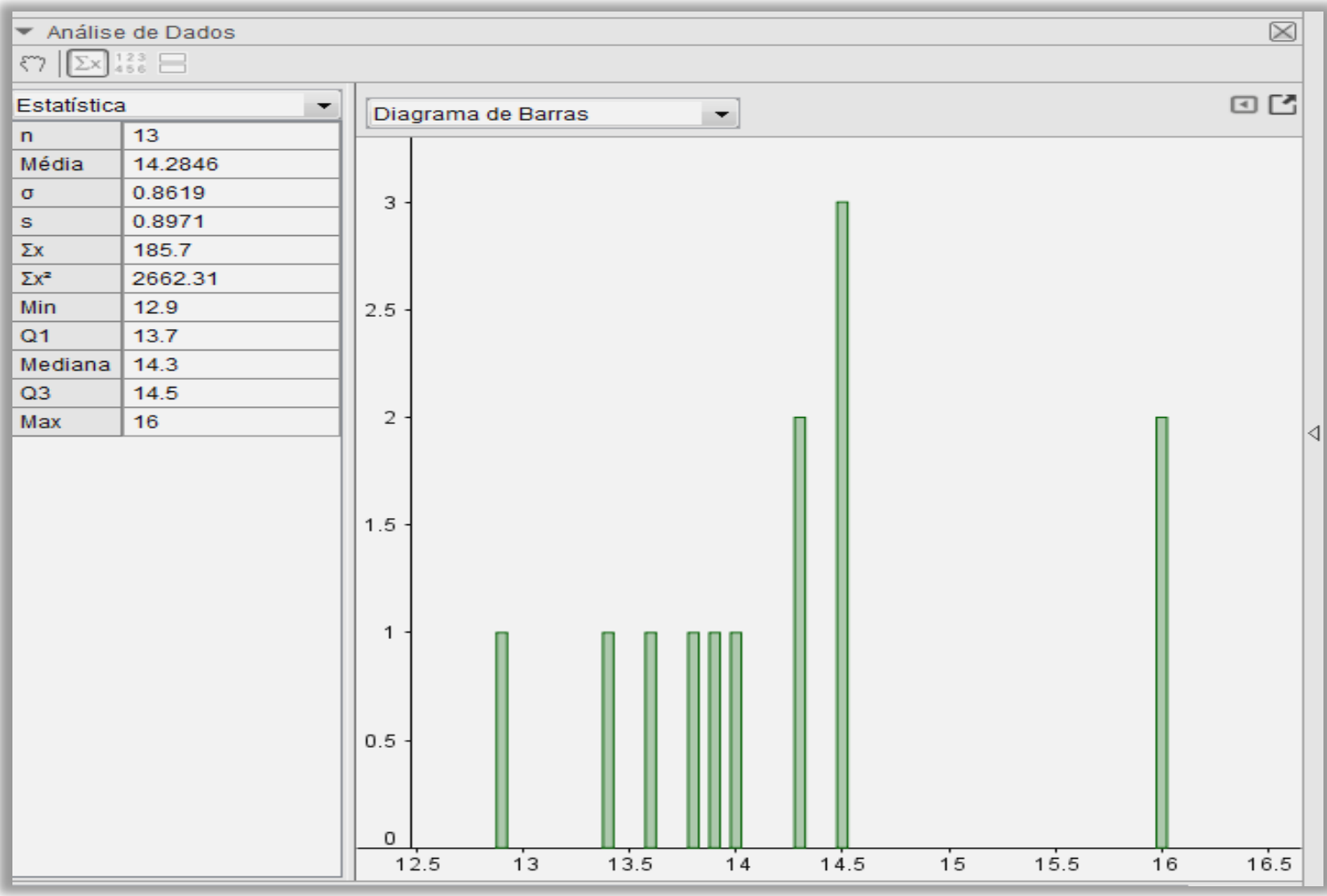

Figura 3: Representações dos dados da atividade 0 no GeoGebra (ARAÚJO, 2018, p. 80-81)

As Figura 2 e 3 ilustram a representação dos dados da Atividade 0 realizada pelos alunos. A partir das figuras, as informações dos dados presentes na tela do GeoGebra permitiram emergir respostas aos questionamentos trazidos na referida atividade. Já tendo encontrado o valor para a média, foi solicitado que os alunos relacionassem o valor encontrado com os dados. 
[...] o professor questiona: como este número se associa aos dados da atividade?

0 aluno d1 justifica dizendo: o número é um valor próximo aos da tabela.

0 aluno d2 indicou em sua fala: o número encontrado para a média é um valor que é o peso que cada criança tem mais ou menos.

O professor então indagou: o que este "mais ou menos" representa?

O aluno d2 respondeu: é a média do peso das crianças (ARAÚJO, 2018, p. 75)

Visto que os alunos encontraram o valor para a mediana, o questionamento acerca desse valor se assemelha ao questionamento feito acerca do valor encontrado para a média.

O valor encontrado evidencia alguma informação ao olhar para os dados apresentados?

Para responder a essa pergunta, os alunos ficaram por um tempo articulando ideias, neste momento, o aluno d2 dirige-se ao professor:

Aluno d2: O valor da mediana é um número que aparece na lista de peso?

Professor: Qual relação este número tem com a lista de peso?

Professor: E com a lista de pesos ordenados? (ARAÚJO, 2018, p. 77)

"Os alunos sabiam que havia alguma relação, até porque o número aparecia nas listas. Mas foi possível notar que eles não perceberam a relação que o valor encontrado tinha com a lista dos dados em ordem crescente, feita no GeoGebra" (ARAÚJO, 2018, p. 77). No entanto é relevante ressaltar que o aluno d2, após a intervenção do professor, junto ao aluno d1, teve uma percepção da relação, em que o valor encontrado é coincidente com o valor centralizado na lista de pesos ordenados. Aluno d2: o número do meio da lista é o mesmo da mediana.

Neste momento da atividade, os alunos tinham disponível apenas a representação tabular e as listas, resultantes de suas ações sobre a situação proposta. Percebe-se que os alunos fazem relação do valor encontrado com os dados da tabela, de modo que, à luz da Teoria da Situações Didáticas (TSD), eles estavam partindo das representações da tela do GeoGebra para formularem conjecturas que validassem propriedades sobre a relação da média com os dados.

Ainda nessa atividade, foi questionado sobre o que representa uma moda, tomando como referência os dados da atividade representados no GeoGebra, visto que os alunos haviam encontrado um peso modal. Nessa fase da Atividade 0, para responder, os alunos, ao seguirem 0 material de apoio, encontraram além dos procedimentos para construir as representações dos dados em encontrarem as MTC, também questionamentos, tais como: o que representa na lista pesoOrdenado? E com os dados da atividade? 
O material de apoio sugeriu a realização de uma análise univariada dos dados, de modo que, em uma representação gráfica dos dados em diagrama de barras, era possível perceber a relação do peso com a frequência de crianças, possibilitando visualizar a frequência de crianças com o mesmo peso. Questionados sobre a relação da barra maior presente na representação gráfica com o peso encontrado para a moda, os alunos em uma dialética de formulação, perceberam que a barra maior trazia a relação peso e a frequência dos pesos das crianças.

\footnotetext{
O aluno d2 indica: o gráfico se refere ao peso das crianças, a barra maior representa a moda do peso das crianças.

0 aluno d1 em relação à barra maior do gráfico, em sua fala, indica: este número que a barra representa é o número que mais se repete (ARAÚJO, 2018, p. 119).
}

Observa-se que a representação gráfica, como a priori fora pensada, contribuiu para os alunos identificarem e validarem propriedades das MTC, sobretudo em relação à moda, mas também a partir da representação gráfica com a tabela auxiliar que o acompanha, é possível observar as outras MTC, e mais ainda, outras medidas, como as de dispersão, por exemplo de modo que é possível comparar os valores na diferentes janelas do GeoGebra.

Essa discussão sobre o que representa um valor encontrado para as Medidas de Tendência Central (MTC) se estende nas outras atividades e as respostas dadas aos questionamentos sempre fazem alguma referência às representações dos dados no GeoGebra. $A$ atividade 3.1, por exemplo, trata da esperança de vida dos brasileiros ao nascer.

\section{ATIVIDADE 3.1}

Ao acessar a tabela correspondente ao censo de 1980, considere os dados da coluna TOTAL.

\begin{tabular}{|r|l|r|r|r|}
\hline \multicolumn{1}{|c|}{} & \multicolumn{1}{|c}{ A } & \multicolumn{1}{c|}{ B } & \multicolumn{1}{c|}{ C } & \multicolumn{1}{c|}{ D } \\
\cline { 2 - 6 } & CENSO & \multicolumn{1}{c}{1980} & 1980 & \multicolumn{1}{c|}{1980} \\
\hline 2 & & HOMEM & MULHER & TOTAL \\
\hline 3 & BRASIL & 59.8 & 65.8 & 62.8 \\
\hline 4 & NORTE & 58.1 & 63.7 & 60.9 \\
\hline 5 & NORDESTE & 55.4 & 61.4 & 58.3 \\
\hline 6 & SUDESTE & 61.7 & 68.5 & 65.1 \\
\hline 7 & SUL & 63.3 & 69.7 & 66.5 \\
\hline 8 & CENTRO-OESTE & 60.5 & 65.7 & 63.2 \\
\hline \multicolumn{1}{|c|}{ Adaptado: https://biblioteca.ibge.gov.br/visualizacao/livros/liv42597.pdf } \\
\hline
\end{tabular}

a) Qual o valor da esperança de vida ao nascer dos brasileiros, de acordo com o censo 1980?

b) Considerando os valores das regiões na coluna TOTAL, calcule o valor para a média? 
c) Em relação aos valores da esperança de vida ao nascer das regiões do Brasil, o que o valor encontrado para a média representa?

d) O que podemos concluir em relação ao valor da média em um conjunto de dados?

Essa atividade foi elaborada a partir de adaptação de material publicado pelo Instituto Brasileiro de Geografia e Estatística - IBGE (BRASIL, 2009). Ao observar a tabela construída com os dados e o valor encontrado para a média, no GeoGebra, o aluno d1 teve o seguinte raciocínio:

[...] Aluno d1: O valor da esperança de vida ao nascer no Brasil em 1980 é 62.8, que é o mesmo valor da média que achamos.

O professor pergunta: Então diga uma forma de como pode ser calculado o valor para média da esperança de vida dos brasileiros.

Aluno d1: Basta calcular como a gente fez.

Professor: Como?

Aluno d1: Dividindo os valores de todas as regiões por todas as regiões. (ARAÚJO, 2018, p. 116)

Verifica-se que na tabela construída no GeoGebra — na atividade apresentava uma idade representativa para todo o Brasil - ficou evidente a compreensão do processo para encontrar 0 valor para a média, pois, a partir da lista construída na janela de álgebra com base na tabela organizada na planilha, o valor encontrado assemelhou-se com a idade representativa para todo o Brasil, o que favoreceu ao professor institucionalizar esse objeto de estudo.

0 professor institucionaliza: A média no conjunto de dados em que o problema foi proposto, de fato, corresponde ao valor encontrado a partir da soma dos valores apresentados de todas as regiões pela divisão do número de regiões. A média corresponde a uma medida de tendência central, que tem como função representar, de forma resumida, o conjunto de dados de onde ela foi extraída, e em um conjunto de dados qualquer, o processo para obtê-la se assemelha ao descrito na situação proposta, correspondendo à soma dos valores de todos os dados de um conjunto de dados e dividindo pela quantidade de dados que este conjunto apresenta. (ARAÚJO, 2018, p. 119).

Esse processo de institucionalização, embora tenha ocorrido apenas ao final da sequência das atividades, durante a aplicação os alunos traziam em suas respostas conjecturas sobre 0 objeto de estudo, o que contribuiu para o professor institucionalizar.

Acerca da mediana, na Atividade 3.2, ainda sobre a esperança de vida ao nascer nas grandes regiões do Brasil, no questionamento sobre o que indicava o valor encontrado para a 
mediana, os alunos não tiveram dificuldade em responder, de modo que a ação sobre a situação permitiu formular e validar rapidamente suas respostas.

\section{ATIVIDADE 3.2}

A tabela a seguir apresenta a esperança de vida dos brasileiros ao nascer no Censo de 1991.

\begin{tabular}{|r|l|r|r|r|}
\hline 10 & CENSO & 1991 & 1991 & 1991 \\
\hline 11 & & HOMEM & MULHER & \multicolumn{1}{|c|}{ TOTAL } \\
\hline 12 & BRASIL & 63.9 & $\mathbf{7 1 . 3}$ & $\mathbf{6 7 . 6}$ \\
\hline 13 & NORTE & 63.6 & 70.2 & 66.9 \\
\hline 14 & NORDESTE & 59.4 & 66.4 & 62.9 \\
\hline 15 & SUDESTE & 64.4 & 73.4 & 68.9 \\
\hline 16 & SUL & 66.8 & 74.4 & 70.6 \\
\hline 17 & CENTRO-OESTE & 65.3 & 72.1 & 68.7 \\
\hline
\end{tabular}

Adaptado de https://biblioteca.ibge.gov.br/visualizacao/livros/liv42597.pdf

a) Qual valor da coluna TOTAL aparece centralizado, quando ordenamos os valores da esperança de vida ao nascer das regiões?

b) Qual o valor da mediana para a esperança de vida ao nascer dos brasileiros, de acordo com os valores apresentados de cada região na coluna TOTAL, no censo de 1991?

c) Em relação à esperança de vida ao nascer nas regiões do Brasil, o que indica o valor encontrado para a mediana?

d) O que o valor da mediana representa em um conjunto de dados?

As respectivas respostas dos alunos $\mathbf{d} 1$ e $\mathbf{d} 2$, descritas na atividade impressa são ilustradas na Figura 4.

c) Emrelaçãoà esperança de vida ao nascernas regiōes do Brasil, o que indica ovalor encontrado para a mediana? s mesmo valor do total que aporea cintralisado quando gidomo.

c) Emrelaçãoà esperança de vida ao nascernas regiōes do Brasil, o que indica

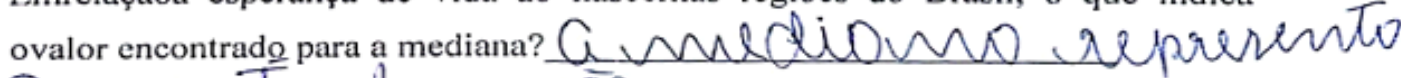

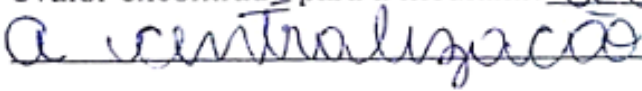

Figura 4: Resposta dos alunos d1 e d2, atividade 3.2 (ARAÚJO, 2018, p.122)

Assim como na Atividade 3.1, na Atividade 3.2 foi solicitado aos alunos que construíssem uma representação gráfica dos dados por meio de uma análise univariada na janela de análise de dados do GeoGebra, a partir dos dados que estavam na planilha do software. 
A representação gráfica, um diagrama de barras, permite questionar se somente com a visualização do gráfico é possível determinar o valor da mediana. A resposta dos alunos é semelhante e indica que não é possível determinar o valor para a mediana a partir da representação gráfica. No entanto, na mesma janela gráfica, na análise dos dados do GeoGebra, os alunos verificaram a tabela que se refere aos valores que o gráfico representa, e que o valor encontrado para a mediana nessa tabela coincide com o valor encontrado anteriormente na janela de álgebra.

Após a discussão sobre o valor para a mediana se apresentar em mais de uma janela do GeoGebra, o professor, tomando como base as representações e as considerações explicitadas pelos alunos "Aluno d1: Centralização dos valores", "Aluno d2: Ele representa a centralização", institucionaliza:

A mediana, em um conjunto de dados qualquer, representa o termo central, pode ser determinada a partir de uma ordenação dos dados, de modo que essa ordem seja crescente ou decrescente, sendo o dado que se encontrar centralizado nestas condições, correspondente à mediana (ARAÚJO, 2018, p. 124).

\section{ATIVIDADE 3.3}

A tabela a seguir refere-se à esperança de vida dos brasileiros ao nascer no ano 2000.

\begin{tabular}{|r|l|r|r|r|}
\hline 19 & CENSO & 2000 & 2000 & 2000 \\
\hline 20 & & HOMEM & MULHER & \multicolumn{1}{l|}{ TOTAL } \\
\hline 21 & BRASIL & 66.6 & 74.2 & 70.4 \\
\hline 22 & NORTE & 66.3 & 72.3 & 69.3 \\
\hline 23 & NORDESTE & 63.4 & 70.8 & 67.1 \\
\hline 24 & SUDESTE & 67.2 & 76.4 & 71.8 \\
\hline 25 & SUL & 68.2 & 76.4 & 72.3 \\
\hline 26 & CENTRO-OESTE & 67.9 & 75.1 & 71.5 \\
\hline
\end{tabular}

Adaptado de https://biblioteca.ibge.gov.br/visualizacao/livros/liv42597.pdf

a) Em relação à esperança de vida ao nascer para as mulheres nas respectivas regiões, existem valores que se repetem?

b) Qual o valor da moda em relação à esperança de vida ao nascer das mulheres nas regiões do Brasil?

c) Em relação à esperança de vida ao nascer para as mulheres nas regiões do Brasil, o que indica 0 valor da moda encontrada?

d) O que podemos concluir em relação ao valor da moda em conjunto de dados? 


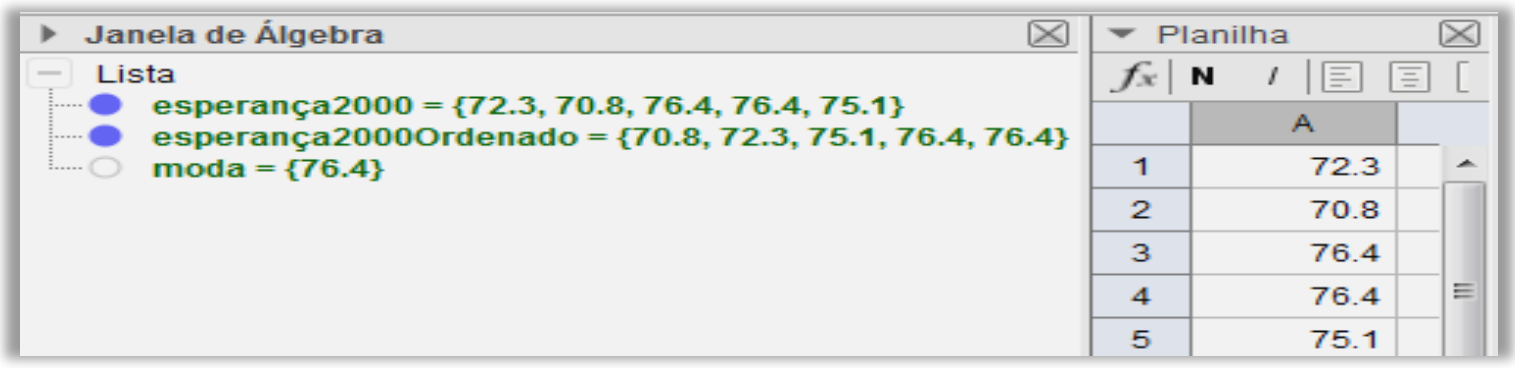

Figura 5: Representações dos dados da atividade 3.3 no GeoGebra (ARAÚJO, 2018, p. 128)

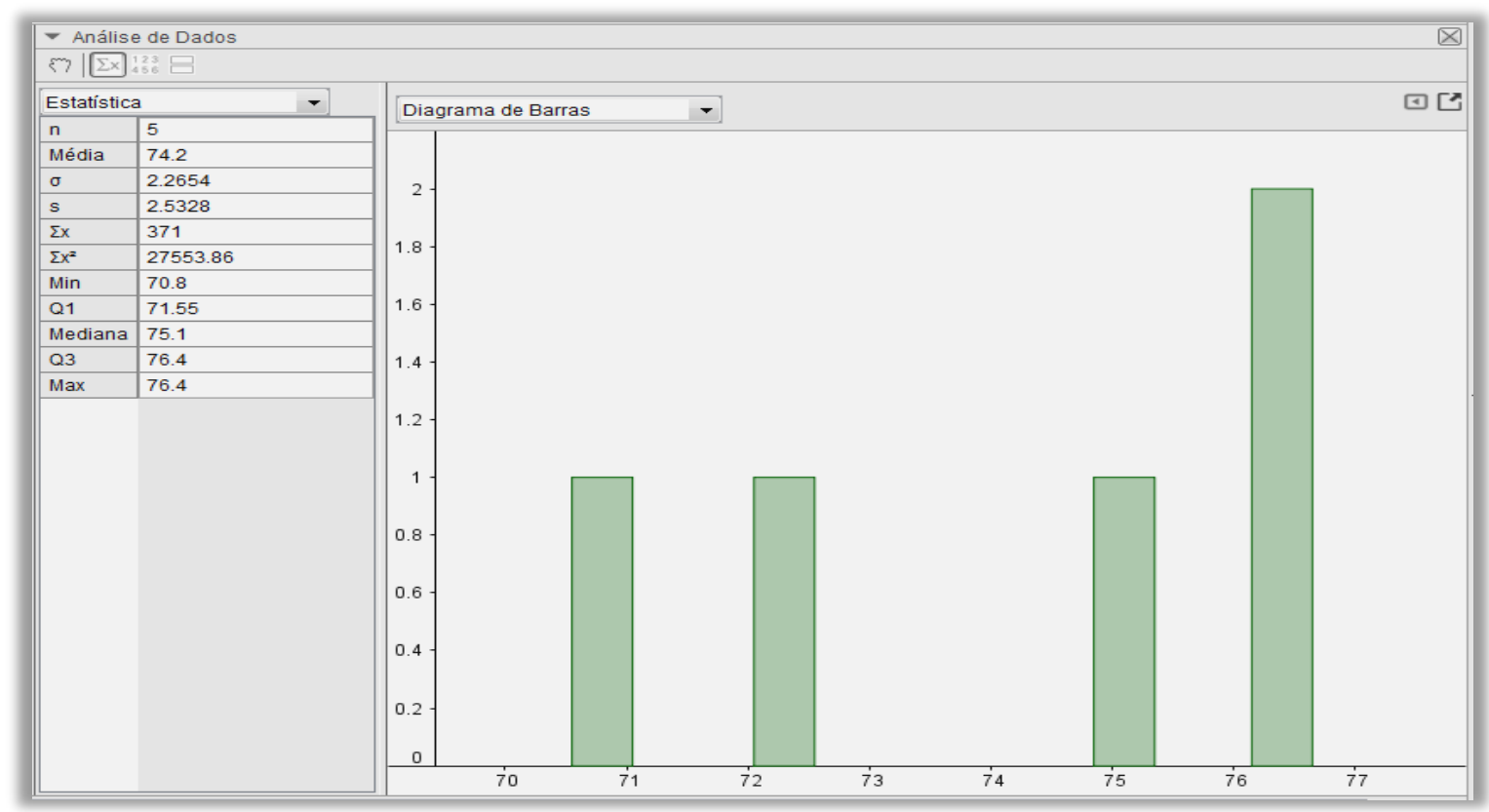

Figura 6: Representações dos dados da atividade 3.3 no GeoGebra (ARAÚJO, 2018, p. 128)

Na Atividade 3.3 a discussão trazida abordou a moda e, assim como nas atividades anteriores, os dados foram digitados na planilha, originando-se uma tabela, que na janela de álgebra possibilitou criar uma lista com os dados além de outra lista com os dados ordenados e a partir de uma das listas encontrar o valor para as MTC.

No caso da Atividade 3.3, o foco está voltado para a moda e a essa medida. Ao resolver essa atividade, os alunos formularam e expuseram suas conjecturas a fim de validá-las. $O$ aluno d1 respondeu: Então a moda é um valor que se repete.

As Figura 5 e 6 referem-se à representação dos dados da Atividade 3.3. Como podemos observar, na representação gráfica é possível conjecturar a moda presente nos dados. De fato, os alunos observaram que, no gráfico, obtido a barra maior coincide com o valor que mais se repete e que esse valor é a moda nos dados, como podemos observar na Figura 7. 
- No gráfico obtido, o que significa a barra maior? Coincide com o valor da moda encontrado? ls númios que bi repete, sim cincide

- No gráfico obtido, o que significa a barra maior? Coincide com o valor da moda encontrado? I gegole que vacies si repetem

Figura 7: Interpretação dos alunos d1 e d2 da representação gráfica dos dados no GeoGebra da atividade 3.3 (ARAÚJO, 2018, p. 129)

"E, neste caso, conforme um questionamento apresentado na atividade, os alunos perceberam que, com a representação gráfica, é possível identificar o valor para a moda" (ARAÚJJO, 2018, p. 129), apenas ao analisar as barras do gráfico, e claro, podendo confirmar sua conjectura na tabela que acompanha a representação gráfica.

Referindo-se às representações dos dados e as repostas dos alunos, "O professor institucionaliza: A moda é, em um conjunto de dados, o valor mais frequente, correspondendo àquele dado que mais se repete em um conjunto qualquer" (ARAÚJO, 2018, p. 130).

\section{Considerações}

A partir das análises realizadas, ao retomar o objetivo deste artigo em apontar contribuições do GeoGebra para o estudo das Medidas de Tendência Central (MTC), identifica-se que "o GeoGebra em uma dialética de ação, possibilitou aos alunos realizaram o tratamento dos dados com facilidade e para questões objetivas, o simples comando no software apresenta 0 resultado" (ARAÚJJO, 2018, p. 134). Ressalta-se que, sob esse aspecto, o software pode ser útil ao aluno para aplicá-lo em outras situações.

Nas janelas do GeoGebra, os valores encontrados para as MTC e as múltiplas representações dos dados favorecem a formulação de conjecturas sobre a relação dos valores encontrados com os dados de sua origem.

Em uma dialética de validação, as representações dos dados no GeoGebra podem permitir aos alunos identificar propriedades das MTC, o que contribui no poder de argumento do aluno acerca do objeto de estudo e sua relação com os dados de origem. Essas representações dos dados, que são múltiplas - tabela, lista, listas ordenadas, gráfico, medidas — possibilita discussões acerca de possíveis propriedades para as MTC, e contribui para o professor institucionalizar o saber. 
Dos resultados obtidos na investigação, as contribuições do GeoGebra para o estudo das MTC vão ao encontro da vantagem didática observada por Bortolossi (2016), em que as múltiplas representações do GeoGebra permitem trabalhar com elementos matemáticos e, neste caso, estatísticos, em sala de aula. Após as discussões e reflexões decorrentes da apresentação do estudo no XIII ENEM, identificamos que essa vantagem didática do GeoGebra é algo que se observa nas dialéticas de ação, formulação e validação e na institucionalização do saber em jogo.

\section{Referências}

ABAR, Celina Aparecida Almeida Pereira. Educação Matemática na era digital. Unión: Revista Iberoamericana de Educación Matemática, n. 27, p. 13-28, out. 2011.

ALMOULOUD, Saddo Ag. Fundamentos da Didática da Matemática. Curitiba: EdUFPR, 2007.

ARAÚJO, José Ronaldo Alves. Atividades para o estudo das Medidas de Tendência Central: uma proposta com o apoio do GeoGebra. 2018. 141f. Dissertação (Mestrado em Educação Matemática) - Faculdade de Ciências Exatas e Tecnologias. Pontifícia Universidade Católica de São Paulo. São Paulo.

ARTIGUE, Michèle. Ingenería didáctica. In: ARTIGUE, Michèle; DOUADY, Régine; MORENO, Luis (Org.). Ingeniería Didáctica en Educación Matemática: un esquema para la investigación y la innovación en la enseñanza y el aprendizaje de las Matemáticas. Bogotá: Una empresa docente \& Grupo Editorial Iberoamérica, 1995, p. 25-60.

BATANERO, Carmen. Significado y comprensión de las Medidas e Posición Central. UNO: Revista de Didáctica de las Matematicas, Granada, n. 25, p. 41-58, jul. 2000.

BORTOLOSSI, Humberto José. O uso do software gratuito GeoGebra no ensino e na aprendizagem de Estatística e Probabilidade. Vidya, Santa Maria, v. 36, n. 2, p. 429-440, jul./dez. 2016.

BRASIL. Instituto Brasileiro de Geografia e Estatística. Indicadores sociodemográficos e de saúde no Brasil. Estudos e Pesquisas: Informação Demográfica e Socioeconômica. n. 25. Brasília: IBGE, 2009.

BRASIL. Ministério da Educação. Secretaria de Educação Básica. Base Nacional Comum Curricular. Brasília: MEC/SEB, 2017.

BRASIL. Ministério da Educação. Secretaria de Educação Fundamental. Parâmetros Curriculares Nacionais: Matemática. Brasília: MEC/SEF, 1998.

BROUSSEAU, Guy. Fondements et méthodes de la didactique des Mathématiques. Researches en Didactique des Mathématiques, v. 7, n. 2, p. 33-115, 1986. 
GODOY, Arllda Schmidt. Introdução à pesquisa qualitativa e suas possibilidades. Revista de Administração de Empresas, São Paulo, v. 35, n. 2, p. 57-63, mar./abr. 1995.

LOPES, Celi Aparecida Espasandin. Os desafios para Educação Estatística no currículo de Matemática. In: ALMOULUOD, Saddo Ag; COUTINHO, Cileda de Queiroz e Silva; LOPES, Celi Aparecida Espasandin. (Org.). Estudo e reflexões em Educação Estatística. Campinas: Mercado de Letras, 2010, p. 47-64.

MACHADO, Silvia Dias Alcantara. Engenharia Didática. In: MACHADO, Silvia Dias Alcantara. (Org.) Educação Matemática: uma (nova) introdução. São Paulo: EDUC, 2015, p. 233-247.

POMMER, Wagner Marcelo. A Engenharia Didática em sala de aula: elementos básicos e uma ilustração envolvendo as Equações Diofantinas Lineares. São Paulo, 2013.

RIBACIONKA, Márcia Cristina dos Santos. Uma proposta de webquest para a introdução ao letramento estatístico na EJA. 2010. 210f. Dissertação (Mestrado em Ensino de Matemática) Faculdade de Ciências Exatas e Tecnologias. Pontifícia Universidade Católica de São Paulo. São Paulo.

SÃO PAULO (Estado). Secretaria de Estado da Educação. Currículo do Estado de São Paulo: Matemática e suas tecnologias. 1. ed. atualizada. São Paulo: SEE, 2011. 